\title{
REQUIREMENT FOR PKC EPSILON IN KRAS-DRIVEN LUNG TUMORIGENESIS
}

Rachana Garg ${ }^{1}$, Mariana Cooke ${ }^{1}$, Shaofei Wang ${ }^{1}$, Fernando Benavides ${ }^{2}$, Martin C. Abba ${ }^{3}$, Michelle Cicchini ${ }^{4}$, David M. Feldser ${ }^{4}$ and Marcelo G. Kazanietz ${ }^{1 *}$

${ }^{1}$ Department of Systems Pharmacology and Translational Therapeutics, Perelman School of Medicine, University of Pennsylvania, Philadelphia, PA 19104, USA.

2 Department of Epigenetics and Molecular Carcinogenesis, The University of Texas MD Anderson Cancer Center, Smithville, TX 78957, USA.

${ }^{3}$ Centro de Investigaciones Inmunológicas Básicas y Aplicadas, Universidad Nacional de La Plata, CP1900, La Plata, Argentina.

${ }^{4}$ Department of Cancer Biology, Abramson Family Cancer Research Institute, Perelman School of Medicine, University of Pennsylvania, Philadelphia, PA 19104, USA.

Word count main text: 2,454 words (maximum: 2,500 words).

Word count abstract: 199 words (maximum: 250 words).

Total number of figures: 4 (maximum: 4).

Running title: $\mathrm{PKC} \varepsilon$ and KRas in lung cancer.

Keywords: PKCE, KRas, carcinogens, mice, lung cancer, adenocarcinoma.

Competing interests: The authors declare no conflict of interest.

Funding support: This work was supported by grants R01-ES026023, R01-CA189765 and R01CA196232 from the National Institutes of Health (M.G.K.), R01-CA193602, R01-CA222503 from the National Institutes of Health and LCD400095 from the American Lung Association (D.M.F.), T32ES019851 from National Institutes of Health (M.C.), and PICT-2015-0149 from the Argentine National Agency of Scientific and Technological Promotion (M.C.A.). The Laboratory Animal Genetic Services located at MD Anderson Cancer Center is supported by P30 CA16672 DHHS/NCI Cancer Center Support Grant (F.B).

* Correspondence and reprints requests should be addressed to: Marcelo G. Kazanietz (marcelog@upenn.edu) at the Department of Systems Pharmacology and Translational Therapeutics, Perelman School of Medicine, University of Pennsylvania, 1256 Biomedical Research Building II/III, 421 Curie Blvd., Philadelphia, PA 19104-6160. Phone: (215)-898-0253. 


\begin{abstract}
Non-small cell lung cancer (NSCLC), the most frequent subtype of lung cancer, remains a highly lethal malignancy and one of the leading causes of cancer deaths worldwide. Mutant KRAS is the prevailing oncogenic driver of lung adenocarcinoma, the most common histological form of NSCLC. In this study, we examined the role of $\mathrm{PKC} \varepsilon$, an oncogenic kinase highly expressed in NSCLC and other cancers, in KRAS-driven tumorigenesis. Notably, database analysis revealed an association between $\mathrm{PKC} \varepsilon$ expression and poor outcome in lung adenocarcinoma patients specifically having KRAS mutation. By generating a PKCE-deficient, conditionally activatable allele of oncogenic $\operatorname{Kras}\left(L S L-K_{r a s}{ }^{G 12 D} ; \mathrm{PKC}^{-/-}\right.$mice $)$we were able to demonstrate the requirement of $\mathrm{PKC} \varepsilon$ for Kras-driven lung tumorigenesis in vivo, which is consistent with the impaired transformed growth observed in PKCE-deficient KRAS-dependent NSCLC cells. Moreover, PKCe-knockout mice were found to be less susceptible to lung tumorigenesis induced by benzo[a]pyrene, a carcinogen that induces mutations in Kras. Mechanistic analysis using RNA-Seq revealed little overlapping for PKCE and KRAS in the control of genes/biological pathways relevant in NSCLC, suggesting that a permissive role of $\mathrm{PKC} \varepsilon$ in $K R A S$-driven lung tumorigenesis may involve non-redundant mechanisms. Our results thus highlight the relevance and potential of targeting PKC $\varepsilon$ for lung cancer therapeutics.
\end{abstract}




\section{INTRODUCTION}

Lung cancer is the leading cause of cancer-related deaths worldwide, accounting for 2.1 million new cases and 1.8 million deaths annually. Non-small cell lung cancer (NSCLC) is the most common form of lung cancer and constitutes $\sim 85 \%$ of new diagnoses, with adenocarcinomas representing the predominant histological form. The disease is often detected at an advanced metastatic stage, resulting in poor patient prognosis (1). The vast majority of lung cancers are associated with long-term exposure to tobacco smoke and/or other environmental factors, such as benzo[a]pyrene $(\mathrm{B}[\mathrm{a}] \mathrm{P})$ and other polycyclic aromatic hydrocarbons resulting from the combustion of organic matter. Most prevalent genetic alterations in lung adenocarcinomas include mutations in $\operatorname{KRAS}(\sim 25 \%)$, EGFR ( 15\%), PIK3CA, HER2 and BRAF (1-5\%), $A L K$ translocations (3-7\%), and MET and $A X L$ amplifications (1-5\%). KRAS mutations, predominantly in codons $12-13$, are found in approximately $1 / 3$ of lung adenocarcinomas of smokers and have been associated with carcinogen exposure $(1,2)$. Targeted therapy against mutant $K R A S$ has thus far been exceptionally challenging, thus stressing the crucial need to identify $K R A S$ effectors as clinically actionable targets for disease management.

Protein kinase $\mathrm{C}$ epsilon (PKCE), a diacylglycerol (DAG) and phorbol ester regulated kinase, emerged as an oncogenic member of the PKC family, and has been widely regarded as a driver of cell survival, mitogenesis, motility and invasion. PKC $\varepsilon$ has been initially characterized as a transforming oncogene and subsequently recognized as a cancer biomarker, showing overexpression in multiple epithelial tumors, including lung cancer. Studies have shown that aberrantly expressed PKC $\varepsilon$ expression contributes to cancer initiation and progression (3-5). For example, prostate-specific PKCe overexpression in mice leads to the development of preneoplastic lesions that evolve to overt invasive adenocarcinoma in conjunction with loss of the tumor suppressor Pten (6). Transgenic PKCe overexpression in the mouse skin leads to the development of metastatic squamous cell carcinomas and enhances the susceptibility to UV radiation-induced skin cancer (7). The elevated PKC $\varepsilon$ levels in primary NSCLC tumors and cell lines has been linked to highly proliferative, survival and aggressive metastatic phenotypes (35,8). However, the association of PKCe expression with lung cancer oncogenic drivers or the susceptibility to carcinogenic insults remains unknown. 
bioRxiv preprint doi: https://doi.org/10.1101/2020.06.26.173690; this version posted June 27, 2020. The copyright holder for this preprint (which was not certified by peer review) is the author/funder. All rights reserved. No reuse allowed without permission.

Here, we investigated the role of PKCe in lung cancer driven by mutant KRAS. Using a null mutant PKCE mouse model, we were able to define the involvement of PKC $\varepsilon$ in KRasmediated and chemically-induced lung carcinogenesis, thus outlining a permissive role for this kinase in tumor development. 


\section{MATERIALS AND METHODS}

\section{Cell culture}

Authenticated lung adenocarcinoma cell lines were obtained from ATCC, and cultured in RPMI medium supplemented with 10\% FBS, $2 \mathrm{mM}$ glutamine, $100 \mathrm{U} / \mathrm{ml}$ penicillin and 100 $\mu \mathrm{g} / \mathrm{ml}$ streptomycin.

\section{RNAi, transfections and lentiviral infections}

Cells were transfected with RNAi duplexes or infected with shRNA lentiviruses for either PKC $\varepsilon$, KRAS or non-target control. For information about RNAi duplexes and lentiviruses, see Supplementary Data.

\section{Western blots and cell growth assays}

Immunoblotting was carried out as described in (9). Details about the commercial antibodies are presented in Supplementary Data. Liquid colony formation (anchorage-dependent) and soft agar (anchorage-independent) growth assays have been previously described (6, see also Supplementary Data).

\section{Lung tumorigenesis studies}

LSL-Kras ${ }^{G 12 D}$ mice (The Jackson Laboratory) were crossed with PKCE KO mice

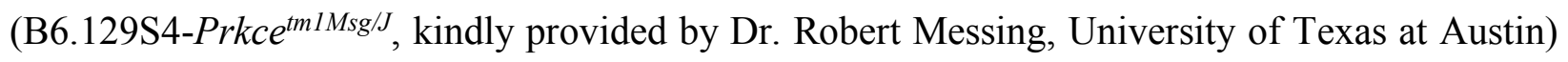
to generate the different experimental genotypes. To initiate $\mathrm{Kras}^{\mathrm{G} 12 \mathrm{D}}$ transgene expression, AdCre $\left(1.2 \times 10^{4} \mathrm{pfu}\right)$ was inoculated intratracheally and lesion formation analyzed 32 week later.

For carcinogenesis studies, PKCE KO mice (B6.129S4-Prkce $\left.e^{t m I M s g / J}\right)$ introgressed into an A/J background were treated with B[a]P (1 mg/ml, i.p., once/week for 4 weeks). Lesion analysis was done 20 weeks later. For speed congenic approach, see Supplementary Data.

\section{RNA-Seq}

Directional RNA-Seq library construction and sequencing was carried out at the UPenn NGS Core. Detailed methodological and bioinformatics analysis is presented as Supplementary Data. 
bioRxiv preprint doi: https://doi.org/10.1101/2020.06.26.173690; this version posted June 27, 2020. The copyright holder for this preprint (which was not certified by peer review) is the author/funder. All rights reserved. No reuse allowed without permission.

\section{Statistical analysis}

ANOVA was performed using GraphPad Prism software built-in analysis tools. $p$ values are indicated in the figure. 


\section{RESULTS AND DISCUSSION}

\section{$P R K C E$ predicts poor outcome in mutant $K R A S$ human lung adenocarcinoma}

$K R A S$ mutations are the most frequent oncogenic alterations reported in human lung adenocarcinoma and are often found in precancerous lesions such as atypical adenomatous hyperplasia (10). Kras mutations, primarily in codon 12, are also detected in spontaneous and chemically-induced mouse lung tumors (2). Since PKCE is up-regulated in human lung adenocarcinoma cell lines and tumors $(4,5,8)$, we intended to ascertain if there exists any potential expression correlations with patient survival using publicly available datasets. For this analysis, we only selected samples with known PRKCE expression, KRAS mutational status and overall survival data, with a minimal follow-up of 10 months. Primary lung adenocarcinomas were first divided into low PRKCE and high PRKCE according to their median expression levels. Kaplan-Meier analysis of the overall population revealed no significant differences between patients with low and high PRKCE expression (Fig. 1A, left panel). Patients were then stratified according to their $K R A S$ mutational status, totaling 352 wild-type $K R A S$ and 73 mutant $K R A S$ cases $\left(43 \% K R A S^{\mathrm{G} 12 \mathrm{C}}, 28 \% K R A S^{\mathrm{G} 12 \mathrm{~V}}, 10 \% K R A S^{\mathrm{G} 12 \mathrm{D}}, 10 \% K R A S^{\mathrm{G} 12 \mathrm{~A}}, 5 \% K R A S^{\mathrm{G} 12 \mathrm{C}}\right.$, $2 \% K R A S^{\mathrm{G} 12 \mathrm{R}}$ and $2 \% K R A S^{\mathrm{G} 12 \mathrm{Y}}$ ). Remarkably, whilst relatively similar outcomes were observed in patients with wild-type $K R A S$ (Fig. 1A, middle panel), striking differences depending on $P R K C E$ expression were found in patients with mutant $K R A S$ tumors. Indeed, mutant $K R A S$ patients with high $P R K C E$ expression showed significantly worse survival compared to those having low PRKCE expression ( $40 \%$ vs. 90\% survival at ten years after diagnosis; Fig. 1A, right panel). Therefore, high PRKCE expression is indicative of poor prognosis in mutant KRAS patients.

\section{Genetic deletion of PKC $\mathrm{P}$ inhibits Kras-mediated lung tumorigenesis in mice}

While PKC isozymes, including PKCe, have been mostly implicated in tumor promotion, emerging evidence suggests a potential role for this kinase in tumor initiation $(3,6)$. Having observed an association between PRKCE expression and poor outcome in KRAS mutant patients, we next examined the involvement of PKCE in Kras-dependent formation of lung adenocarcinomas using a mouse model. Towards this goal, we employed a conditional mutant Kras mice $\left(L S L-K_{r a s}^{G 12 D}\right)$ (11) and examined if tumorigenesis ensues in a PKC $\varepsilon$-null 
background. We therefore intercrossed $L S L-\operatorname{Kras}^{G 12 D}$ mice with PKCE KO mice (B6.129S4Prkce $\left.^{t m I M s g / J}\right)$ to generate cohorts of $L S L-K_{r a s}^{G 12 D} ; P_{r k c e^{+/+}}, L S L-K_{r a s}^{G 12 D} ; P r k c e^{+/-}$and LSL$\operatorname{Kras}^{G 12 D} ;$ Prkce $^{-/-}$mice. Expression of the oncogenic Kras ${ }^{\mathrm{G} 12 \mathrm{D}}$ allele in lungs was achieved following Ad-Cre intratracheal instillation of adenoviral Cre (Ad-Cre), which removes the LoxStop-Lox (LSL) cassette (Fig. 1B). LSL-Kras ${ }^{G 12 D} ;$ Prkce $^{+/+}$mice displayed characteristic lesions as reported previously in Kras mutant mice (11), including pulmonary adenoma and atypical adenomatous hyperplasia (46\% of lesions) as well as bronchiolar/alveolar hyperplasia (54\% of lesions). Remarkably, there was a significant reduction in the overall lesions in $L S L$ $\operatorname{Kras}^{G 12 D} ;$ Prkce $^{+/-}$mice, and essentially no lesions were detected in LSL-Kras ${ }^{G 12 D}$;Prkce ${ }^{-/-}$mice (Figs. 1C). Thus, genetic deletion of the Prkce gene in mice impaired Kras-mediated lung tumorigenesis. Kaplan-Meier analysis revealed a median survival of 284 days for control $L S L$ Kras $^{G 12 D} ;$ Prkce $^{+/+}$mice. However, loss of either one or two Prkce alleles significantly extended mice lifespan, with a median survival of 368 and 470 days, respectively (Fig. 1D).

\section{$\mathrm{PKC} \varepsilon$ is required for $\mathrm{B}[\mathrm{a}] \mathrm{P}$-induced lung carcinogenesis}

Thus far, an unresolved question is whether PKCe contributes to lung tumorigenesis induced by chemical carcinogens. To answer this, we employed a known B[a]P-induced lung tumorigenesis model. Since B6.129S4 genetic background is poorly sensitive to the action of carcinogens, we crossed the PKCe allele into the $\mathrm{A} / \mathrm{J}$ background, which is highly susceptible to chemical carcinogenesis (12). Using a speed congenic procedure, a 97\% A/J background was achieved for the PKCe KO mice (Fig. S1).

Next, $\mathrm{A} / \mathrm{J} \mathrm{PKC} \varepsilon^{+/+}, \mathrm{PKC}^{+/-}$and $\mathrm{PKC}^{-/-}$mice $(6-8$-weeks) were treated with $\mathrm{B}[\mathrm{a}] \mathrm{P}$ (Fig. 2A) and their lungs analyzed 20 weeks post carcinogen treatment (Fig. 2B). Nearly all PKCE ${ }^{+/+}$ mice (95\%) developed lung lesions. Remarkably, the incidence of lesions was markedly diminished upon loss of one or two Prkce alleles. The incidence of B[a]P-induced adenomas in $\mathrm{PKC}^{+/+}, \mathrm{PKC}^{+/-}$and $\mathrm{PKC}^{-/-}$mice was $76 \%, 50 \%$ and $31 \%$, respectively. A similar trend was observed for the incidence of hyperplastic lesions developed in the various groups (Fig. 2C). An average of 4.5 lung lesions was found in $\mathrm{PKCE}^{+/+}$mice, whereas the lesion multiplicity was significantly reduced in $\mathrm{PKC} \varepsilon^{+/-}$and $\mathrm{PKC}^{-/-}$mice (Fig. 2D). The observed inhibition of chemically-induced lung tumor formation even upon the loss of a single Prkce allele is a strong 
indicator that PKCE expression levels are key to determine susceptibility to the chemical carcinogen.

\section{Silencing PKCE expression reduces features of transformation of $K R A S$ mutant NSCLC cells}

To further assess the involvement of PKC $\varepsilon$ in $K R A S$-mediated phenotypes, we examined the PKCe requirement for growth of $K R A S$ mutant human lung adenocarcinoma cells. Four different siRNAs were used to silence the expression of either KRAS (K1-K4) or PKCe ( $\varepsilon 1$ ع4) in H2009 cells (Fig. 3A, left panel). RNAi duplexes that cause a major knockdown in KRAS expression (K1 and $\mathrm{K} 3$ ) led to a prominent reduction in anchorage-dependent growth relative to cells transfected with a non-target control (NTC), as expected from the KRAS dependency of this cell line (13). A smaller effect was observed with RNAi duplexes that were less efficient to silence KRAS (K2 and K4). Similar decrease in H2009 cells anchorage-dependent growth was observed upon PKCE depletion, albeit the extent varied with different RNAi duplexes (Fig. 3A, right panel). Inhibition of colony formation following KRAS or PKC $\varepsilon$ RNA silencing was also observed in KRAS mutant NSCLC cell lines H358 and H441 (Figs. S2A, S2B, S2D and S2E). Notably, analysis of anchorage-independent growth in soft agar also revealed a consistent dependency on both KRAS and PKCe in H2009 (Fig. 3B) and H358 cells (Fig. S2C). H441 cells did not form colonies in soft agar (data not shown). For validation, we generated five PKC $\varepsilon$ stably depleted H2009 cell lines using shRNA lentiviruses. These cell lines displayed in all cases reduced anchorage-dependent and anchorage-independent growth relative to cells transduced with NTC shRNA lentivirus (Fig. S3). Taken together, our data strongly support the contention that PKC $\varepsilon$ is required for KRAS-dependent transformed growth of NSCLC cells.

Studies implicated PKCs in mitogenic and survival signaling in cancer cells (3-5). However, whether PKCe mediates signaling events in KRAS mutant NSCLC cells remains undetermined. To our surprise, silencing PKC $\varepsilon$ in KRAS mutant H2009 cells failed to reduce phosphorylated (active) levels of Erk, Akt and STAT3, well-established downstream effectors of KRAS (Fig. 3C). Likewise, the activation status of these effectors was not reduced upon treatment with either the "pan" PKC inhibitor (GF109203X) or the cPKC inhibitor Gö6976 (Fig. 3D). Rather, phospho-Akt levels were slightly elevated upon PKC inhibitors treatment. This effect is consistent with the known inhibition of Akt by PKC $\alpha$ (14), the only cPKC expressed in 
these cells (9). Similar results were observed in H358 and H441 cells (data not shown). Therefore, regardless of the PKCe requirement for NSCLC cell growth and lung tumorigenesis, this kinase or other PKCs may not act as a downstream effector of KRAS for key mitogenic and survival signaling pathways.

\section{Differential control of gene expression by PKC $\varepsilon$ and KRAS in NSCLC cells}

As a next step in our search for potential common mechanisms by which KRAS and PKC $\varepsilon$ regulate transformed growth in NSCLC cells, we explored global gene expression changes. While KRAS-dependent signatures have been established, including in lung cancer $(15,16)$, studies suggested a limited involvement of PKCE in controlling gene expression compared to other PKC family members $(9,17)$. Using RNA-Seq, we carried out gene expression analysis in $\mathrm{H} 2009$ cells subjected to PKCE or KRAS depletion with two different duplexes in each case. To identify differentially regulated expression, we used the edgeR test (FDR $<0.05$, cut off: 2-fold change relative to NTC). This analysis revealed 260 differentially regulated genes (148 up- and 112 down-regulated) by both KRAS RNAi duplexes, whereas relatively less effect was observed upon PKCE silencing (73 deregulated genes, 38 up- and 35 down-regulated). As expected, KRAS and $\mathrm{PKC} \varepsilon$ levels were among the down-regulated genes, with nearly complete depletion with each RNAi duplex (Fig. 4A). Heatmaps of deregulated transcripts are shown in Figs. 4B, and a complete list of genes is presented in Table S1. The limited involvement of PKCE in gene expression agrees with our recent study in NSCLC cells using the PKC $\varepsilon$-specific ligand AJH-836 (9). Interestingly, a small overlap (15 genes) was found between KRAS- and PKC $\varepsilon$ regulated genes, in all cases genes up-regulated upon specific silencing (Fig. 4C).

Using InnateDB, we carried out automated annotation and functional enrichment analysis of the differentially expressed genes. The top statistically significant bioprocesses regulated by KRAS included AP1 transcription factor targets, extracellular matrix (ECM) organization and degradation, integrin- $\beta 1$ cell surface interaction, as well as Jak-STAT, ErbB and RAS signaling pathways. Despite the small number of genes affected by PKCE silencing, we identified a few statistically significant bioprocesses regulated by this kinase, including integrin cell surface/ECM interactions and VEGFR/PDGFR signaling pathways (Fig. 4D, upper panel; see Table S2 for complete list). A few bioprocesses were found to be commonly regulated by KRAS and $\mathrm{PKC} \varepsilon$, though the number of genes involved is relatively small, particularly in the case of 
PKCE (Fig. 4D, lower panel). Therefore, it is reasonable to speculate that the requirement of PKC $\varepsilon$ for KRAS-mediated growth and tumorigenesis does not rely on common transcriptional genetic programs.

\section{Final remarks}

Our findings revealed a functional association between KRAS and PKC $\varepsilon$ contributing to the development of lung cancer. The reduced number of Kras-driven and B[a]P-induced lung lesions in a PKCE-deficient background strongly argues for a key permissive role of this kinase in tumor initiation. Although a comprehensive mechanistic assessment of the hierarchical relationship between KRAS and PKCE has yet to be pursued, the fact that loss of PKCE does not substantially affect the activation status of KRAS signaling effectors or the expression of KRASregulated genes argues against PKCe acting as a KRAS downstream effector. Rather, we speculate that both KRAS and PKCe act in a coordinated manner through parallel pathways, whereby $\mathrm{PKC} \varepsilon$ likely provides a facilitating input (i.e. a survival signal) for oncogenesis. The overlap in KRAS and PKCe bioprocesses, including those related to ECM, integrins and adhesion, together with the known PKCe involvement in integrin function and anoikis resistance $(3,18,19)$, may throw light on the molecular basis of the KRAS-PKCE functional interaction.

NSCLC tumors display elevated PKCE levels $(3-5,8)$ According to our dataset analysis, PKC $\varepsilon$ may represent a prognostic biomarker of poor outcome specifically in KRAS mutant lung adenocarcinoma patients. We speculate that $\mathrm{PKC} \varepsilon$ contributes to disease development in a coordinated manner with specific genetic alterations, as recently shown for Pten-deficient prostate cancers (6), and serves as a marker for stratification of patients based on its expression. Notably, the reported reversion of Ras-mediated transformed phenotypes by pharmacological inhibition of $\mathrm{PKC \varepsilon}$ (20) highlights unique opportunities for therapeutic interventions involving PKC $\varepsilon$ targeting. Given the relevance of KRAS oncogenic signaling in the progression of lung adenocarcinomas, digging into the intricacies of $\mathrm{KRAS} / \mathrm{PKC} \varepsilon$ interactions may uncover novel cross-talks between these players and help rationalize the potential for developing PKC $\varepsilon$ targeted therapies for oncogenic Ras-driven malignancies. 


\section{REFERENCES}

1. Gridelli C, Rossi A, Carbone DP, Guarize J, Karachaliou N, Mok T, et al. Non-small-cell lung cancer. Nat Rev Dis Primers 2015;1:15009.

2. Luch A. Nature and nurture - lessons from chemical carcinogenesis. Nat Rev Cancer 2005;5:113-25.

3. Jain K, Basu A. The Multifunctional Protein Kinase C-epsilon in Cancer Development and Progression. Cancers (Basel) 2014;6:860-78.

4. Bae KM, Wang H, Jiang G, Chen MG, Lu L, Xiao L. Protein kinase C epsilon is overexpressed in primary human non-small cell lung cancers and functionally required for proliferation of nonsmall cell lung cancer cells in a p21/Cip1-dependent manner. Cancer Res 2007;67:6053-63.

5. Griner EM, Kazanietz MG. Protein kinase C and other diacylglycerol effectors in cancer. Nat Rev Cancer 2007;7:281-94.

6. Garg R, Blando JM, Perez CJ, Abba MC, Benavides F, Kazanietz MG. Protein Kinase C Epsilon Cooperates with PTEN Loss for Prostate Tumorigenesis through the CXCL13-CXCR5 Pathway. Cell Rep 2017;19:375-88.

7. Verma AK, Wheeler DL, Aziz MH, Manoharan H. Protein kinase Cepsilon and development of squamous cell carcinoma, the nonmelanoma human skin cancer. Mol Carcinog 2006;45:381-88.

8. Caino MC, Lopez-Haber C, Kissil JL, Kazanietz MG. Non-small cell lung carcinoma cell motility, rac activation and metastatic dissemination are mediated by protein kinase $\mathrm{C}$ epsilon. PLoS One 2012; 7:e31714.

9. Cooke M, Casado-Medrano V, Ann J, Lee J, Blumberg PM, Abba MC, et al. Differential Regulation of Gene Expression in Lung Cancer Cells by Diacyglycerol-Lactones and a Phorbol Ester Via Selective Activation of Protein Kinase C Isozymes. Sci Rep 2019;9:6041.

10. Cooper CA, Carby FA, Bubb VJ, Lamb D, Kerr KM, Wyllie AH. The pattern of K-ras mutation in pulmonary adenocarcinoma defines a new pathway of tumour development in the human lung. J Pathol 1997;181:401-4.

11. Jackson EL, Willis N, Mercer K, Bronson RT, Crowley D, Montoya R, et al. Analysis of lung tumor initiation and progression using conditional expression of oncogenic K-ras. Genes Dev 2001;15:3243-8.

12. Malkinson AM. The genetic basis of susceptibility to lung tumors in mice. Toxicology 1989;54:241-71.

13. Ohm AM, Tan AC, Heasley LE, Reyland ME. Co-dependency of PKCdelta and K-Ras: inverse association with cytotoxic drug sensitivity in KRAS mutant lung cancer. Oncogene 2017;36:4370-8.

14. Tanaka Y, Gavrielides MV, Mitsuuchi Y, Fujii T, Kazanietz MG. Protein kinase C promotes apoptosis in LNCaP prostate cancer cells through activation of p38 MAPK and inhibition of the Akt survival pathway. J Biol Chem 2003;278:33753-62.

15. Sweet-Cordero A, Mukherjee S, Subramanian A, You H, Roix JJ, Ladd-Acosta C, et al. An oncogenic KRAS2 expression signature identified by cross-species gene-expression analysis. Nat Genet 2005;37:48-55.

16. Singh A, Greninger P, Rhodes D, Koopman L, Violette S, Bardeesy N, et al. A gene expression signature associated with "K-Ras addiction" reveals regulators of EMT and tumor cell survival. Cancer Cell 2009; 15:489-500.

17. Caino MC, von Burstin VA, Lopez-Haber C, Kazanietz MG. Differential regulation of gene expression by protein kinase $\mathrm{C}$ isozymes as determined by genome-wide expression analysis. $J$ Biol Chem 2011;286:11254-64. 
18. Ivaska J, Bosca L, Parker PJ. PKCepsilon is a permissive link in integrin-dependent IFN-gamma signalling that facilitates JAK phosphorylation of STAT1. Nat Cell Biol 2003;5:363-9.

19. Ivaska J, Whelan RD, Watson R, Parker PJ. PKC epsilon controls the traffic of betal integrins in motile cells. EMBO J 2002;21:3608-19.

20. Dann SG, Golas J, Miranda M, Shi C, Wu J, Jin G, et al. p120 catenin is a key effector of a RasPKCepsilon oncogenic signaling axis. Oncogene 2014;33:1385-94. 


\section{FIGURE LEGENDS}

Figure 1. PKCE is required for the formation of Kras-driven lung lesions. Panel A. KaplanMeier analysis was carried out in a set of 425 patients with lung adenocarcinomas. Patients were categorized as "PRKCE high" (red lines) and "PRKCE low" (blue lines) according to the median expression of the Affymetrix 206248_at probe. Databases employed: GEO31210, E-MTAB923 and TCGA-LUAD. Left panel, all patients; middle panel, wild-type KRAS patients; right panel, mutant KRAS patients. Panel B. Schematic representation of the protocol for analysis of lung tumorigenesis and survival. To initiate $\mathrm{Kras}^{\mathrm{G} 12 \mathrm{D}}$ transgene expression, Ad-Cre $\left(1.2 \times 10^{4} \mathrm{pfu}\right)$ was inoculated intratracheally in 6-8-week old mice of three different genotypes ( $L S L$ $\operatorname{Kras}^{G 12 D} ; \mathrm{PKC \varepsilon}^{+/+}, L S L-K r a s^{G 12 D} ; \mathrm{PKC \varepsilon}^{+/-}$and $\left.L S L-K r a s^{G 12 D} ; \mathrm{PKC}^{-/-}\right)$. Panel C. Left panel, representative photomicrographs of $\mathrm{H} \& \mathrm{E}$ stained lungs from $L S L-K r a s^{G 12 D} ; \mathrm{PKC} \varepsilon^{+/+}, L S L-$ $\operatorname{Kras}^{G 12 D} ; \mathrm{PKC \varepsilon}^{+/-}$and $L S L-\operatorname{Kras}^{G 12 D} ; \mathrm{PKC \varepsilon}^{-/-}$mice. Magnification: 2X. Right panel, number of lesions in lungs from mice sacrificed 32 weeks after Ad-Cre delivery. Each point represents one mouse. Results are expressed as mean \pm S.E.M. (n=8-11/group). Panel D. Kaplan-Meier analysis of mice survival for a period of 520 days post Ad-Cre delivery $(\mathrm{n}=8 /$ group, $\mathrm{p}<0.05)$.

Figure 2. $\mathrm{B}[\mathrm{a}] \mathrm{P}$-induced lung tumorigenesis is impaired in $\mathrm{PKC} \varepsilon \mathrm{KO}$ mice. $\mathrm{PKC} \varepsilon \mathrm{KO}$ mice (B6.129S4-Prkce $e^{t m l M s g / J}$ ) were introgressed into an A/J background using a speed congenic procedure (see Fig. S1). PKC $\varepsilon^{+/+}, \mathrm{PKC}^{+/-}$and $\mathrm{PKC} \varepsilon^{-/-}$mice (6-8-week old) in $\mathrm{A} / \mathrm{J}$ background were treated with B[a]P (1 mg/ml, i.p., once/week for 4 weeks) and sacrificed 20 weeks later. Excised lungs were subjected to H\&E staining and histopathological analysis at the University of Pennsylvania Comparative Pathology Core. Panel A. Scheme depicting the experimental approach. Panel B. Representative photomicrographs of $\mathrm{H} \& \mathrm{E}$ stained lungs from $\mathrm{PKC} \varepsilon^{+/+}$, $\mathrm{PKC}^{+/-}$and $\mathrm{PKC}^{-/-}$mice 20 weeks after $\mathrm{B}[\mathrm{a}] \mathrm{P}$ treatment. Magnification: 2X. Panel C. Incidence of total lesions, hyperplastic lesions and adenomas. Panel D. Analysis of multiplicity of lesions in different groups. Each point represents one mouse. Results are expressed as mean \pm S.E.M. (n=16-25/group).

Figure 3. PKCE is required for clonogenic and transformed growth of KRAS-mutant NSCLC cells. Panel A. Expression of PKC $\varepsilon$ and KRAS in H2009 cells subjected to RNAi, as 
determined by Western blot (left panel). Anchorage-dependent growth was determined by means of a liquid colony formation. A representative experiment and quantitative analysis are shown. Results are expressed as mean \pm S.E.M. $(\mathrm{n}=4){ }^{*}, \mathrm{p}<0.05$ vs. NTC; **, $\mathrm{p}<0.01$ vs. NTC (right panel). Panel B. Anchorage-independent growth in soft agar. Representative pictures of plates (upper panels) and photomicrographs of colonies (lower panels) are shown. Similar results were observed in two additional experiments. Panel C. H2009 cells were subjected to PKCE RNAi with duplexes $\varepsilon 1, \varepsilon 2, \varepsilon 3$ and $\varepsilon 4$. Forty-eight h later, cells were lysed and subject to Western blot analysis with the indicated antibodies. Left panel, representative experiment. Right panels, densitometric analysis of 3 independent experiments. Results are expressed as mean \pm S.E.M. Panel D. H2009 cells were treated with PKC inhibitors GF109203X (3 $\mu \mathrm{M})$ and Gö6976 (3 $\mu \mathrm{M})$ for either 1 or 3 h. Left panel, representative Western blots with the indicated antibodies. Right panels, densitometric analysis of 3 independent experiments. Results were expressed as mean \pm S.E.M.

Figure 4. Gene expression analysis in PKCE- and KRAS-depleted NSCLC cells. H2009 cells were subjected to PKCE RNAi ( $\varepsilon 1$ or $\varepsilon 3$ duplexes) or KRAS RNAi (K1 or K3 duplexes), and RNA-Seq analysis for gene expression was performed $48 \mathrm{~h}$ after transfection. As controls we used NTC RNAi and parental cells. Three replicates were done for each condition. Panel $A$. Validation of PKC $\varepsilon$ and KRAS silencing from the RNA-Seq data in individual samples. Panel $B$. Heatmap of 73 deregulated genes $(D E G)$ in $\mathrm{H} 2009$ cells subjected to PKCE RNAi depletion (upper panel) or KRAS RNAi depletion (lower panel). The color scale at the bottom of the heatmap is used to represent expression level (green, low expression; red, high expression). Fold-change $>2$; FDR $<0.01)$. Panel $C$. Venn diagram of transcripts commonly modulated among PKC $\varepsilon$ and KRAS silenced H2009 cells. Panel D. Top bioprocess enriched in the PKC $\varepsilon$ and KRAS gene expression signatures. The red dotted line indicates the cut off for statistical significance $(\mathrm{p}<0.05)$ (upper panel). A comparative analysis of the bioprocesses commonly enriched across the PKC $\varepsilon$ and KRAS regulated genes was done using the InnateDB resource (lower panel). 
Figure 1

A
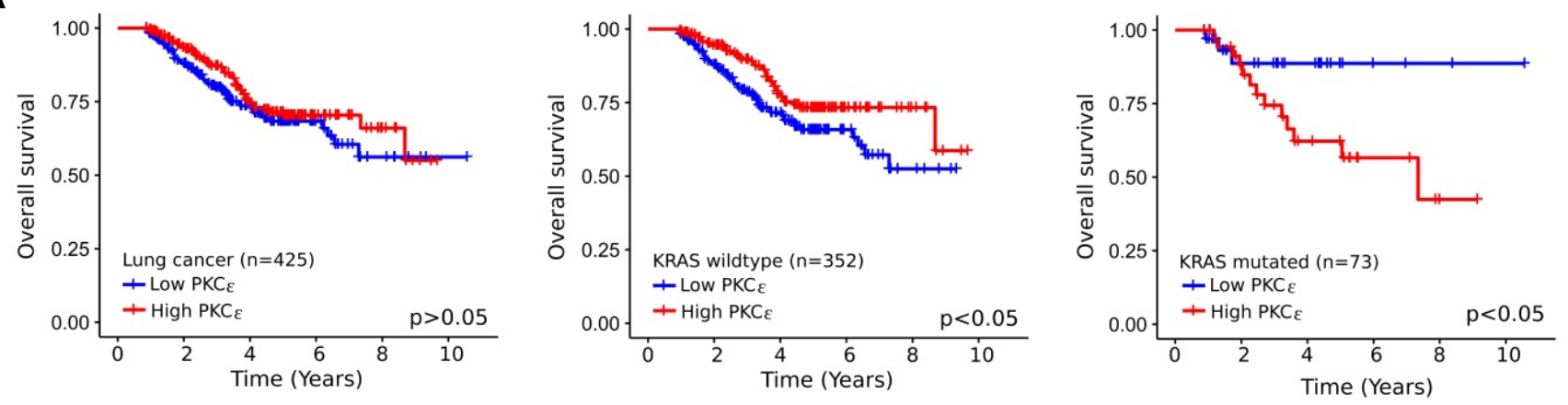

B

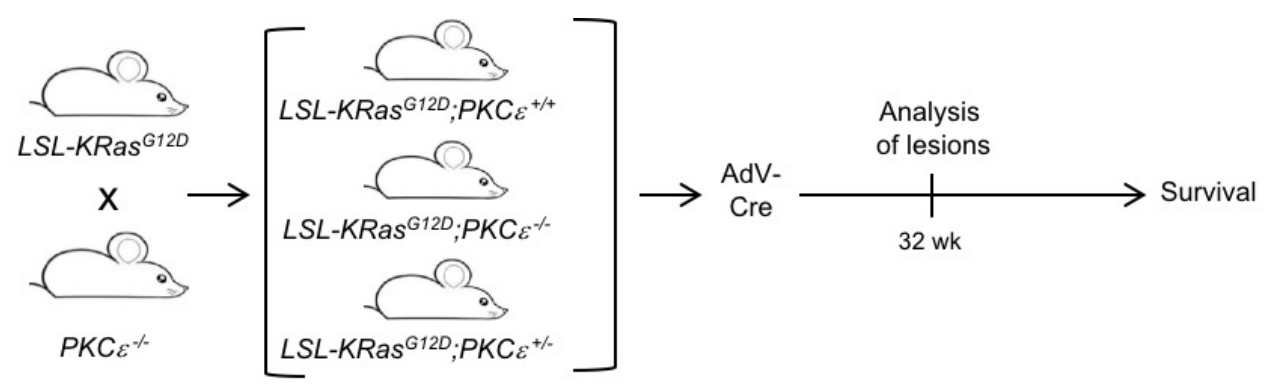

C

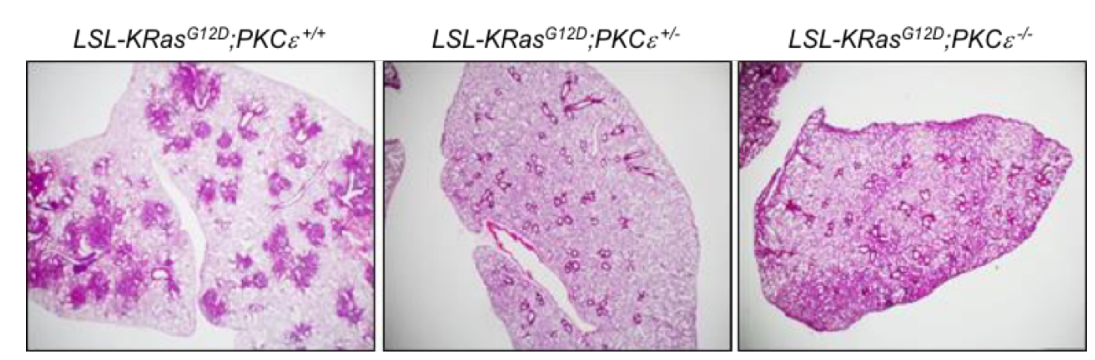

D
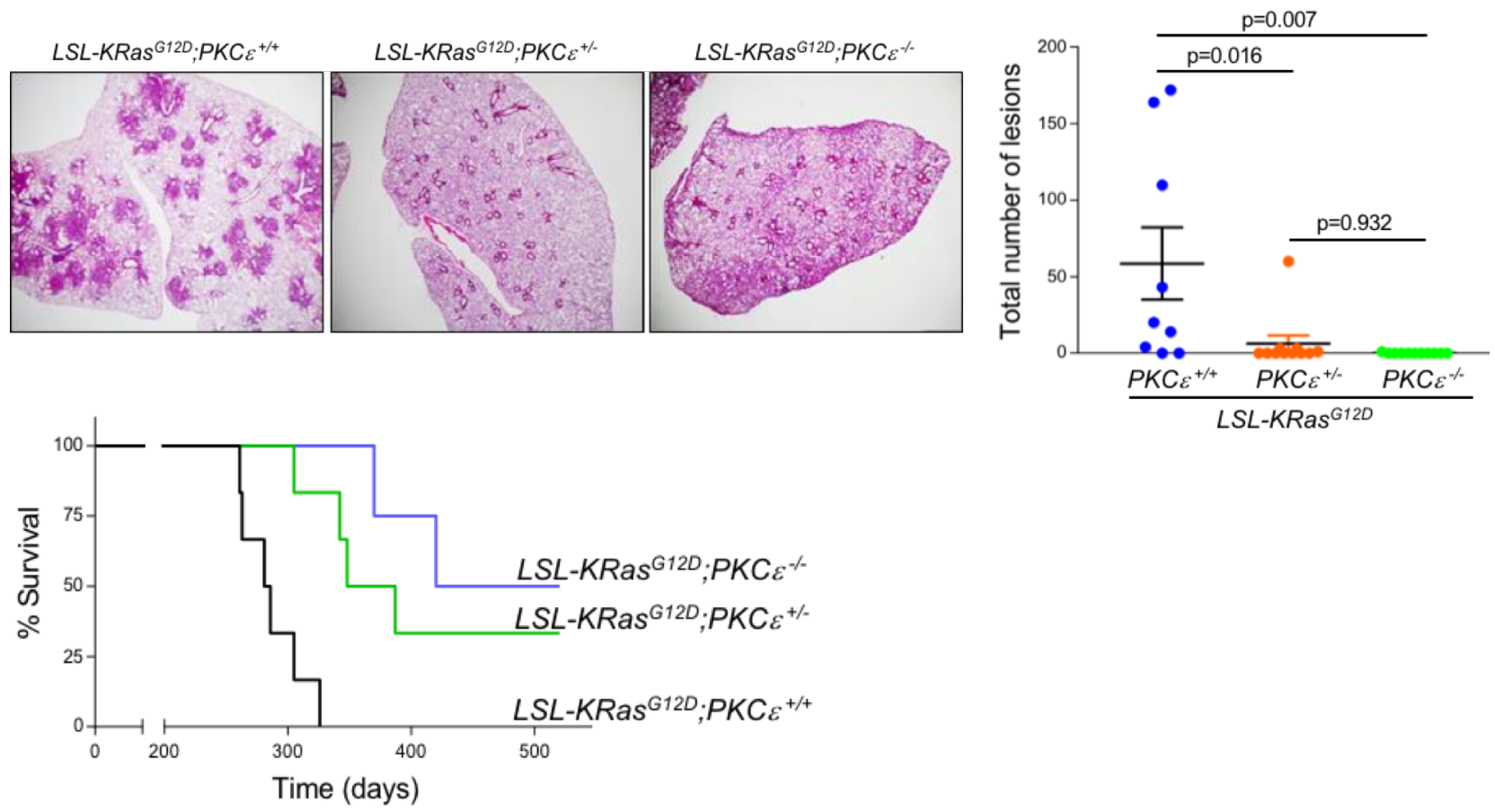
Figure 2

A

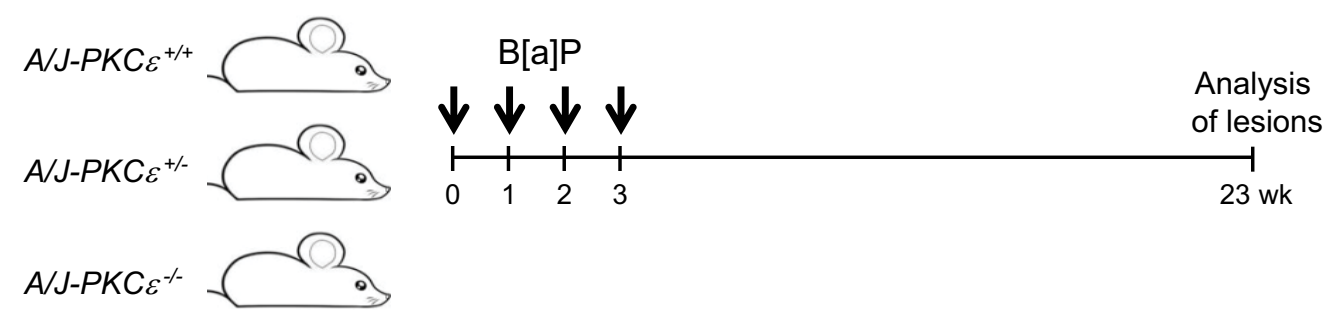

B
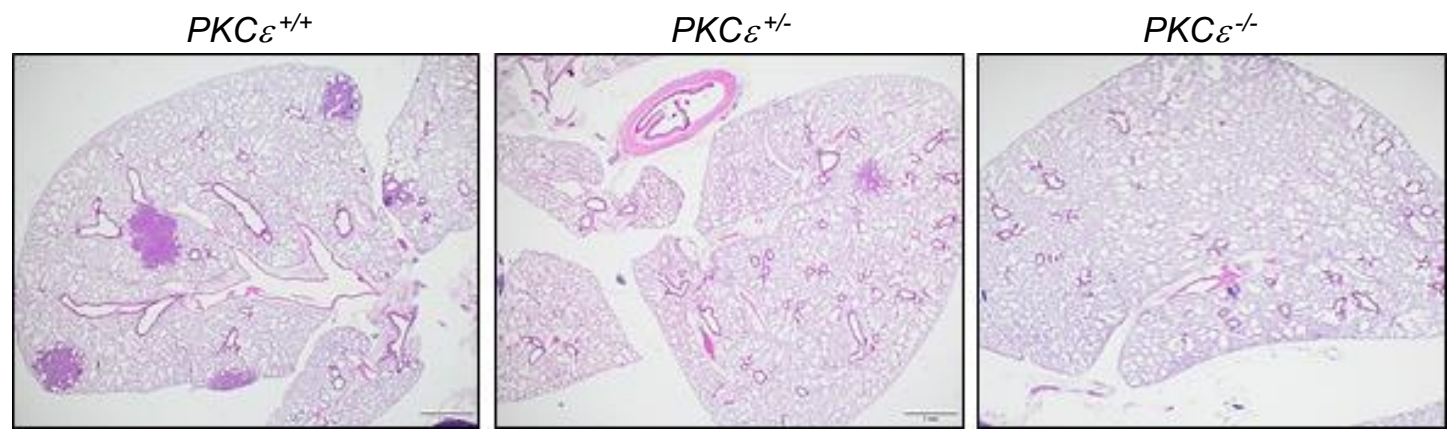

C

All lesions

Hyperplasia

Adenoma
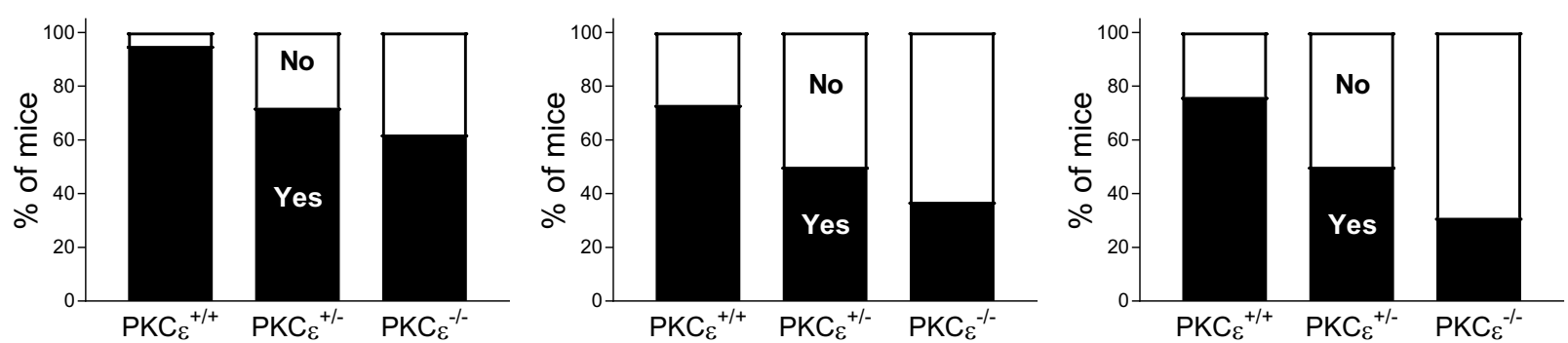

D
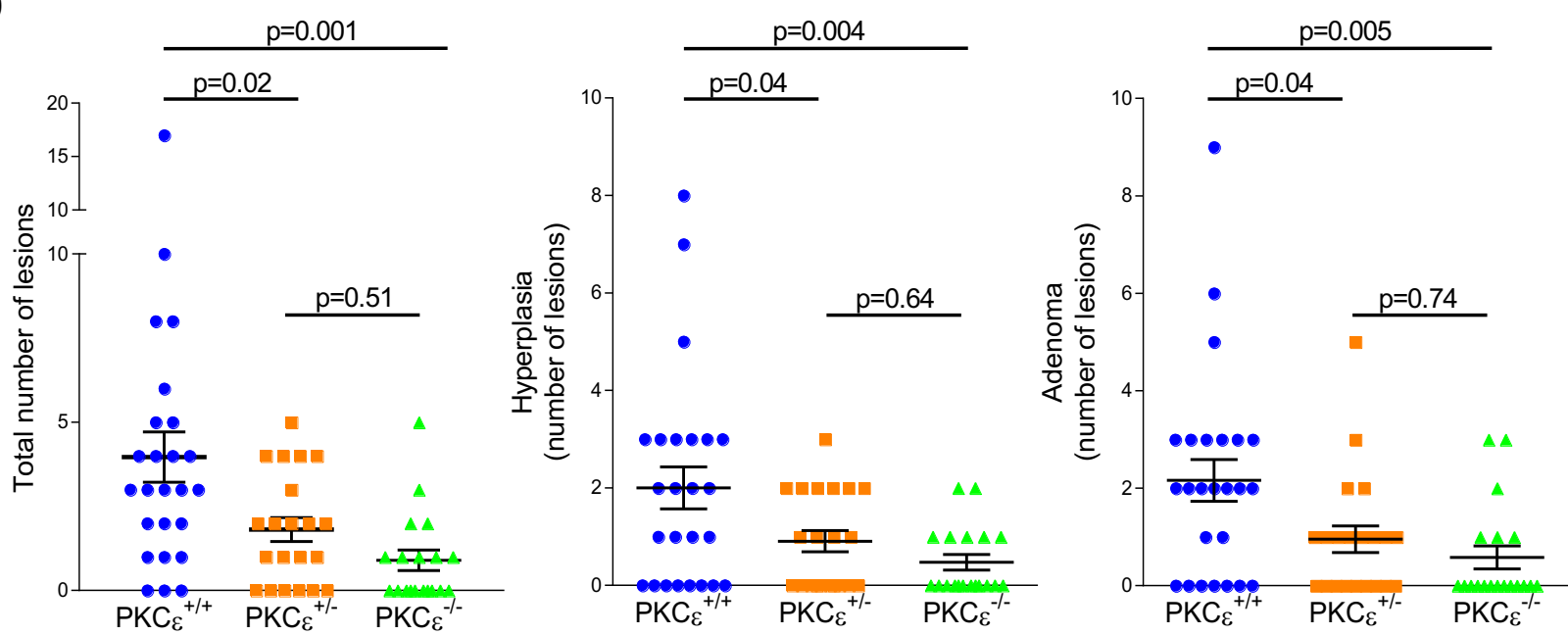
Figure 3

A
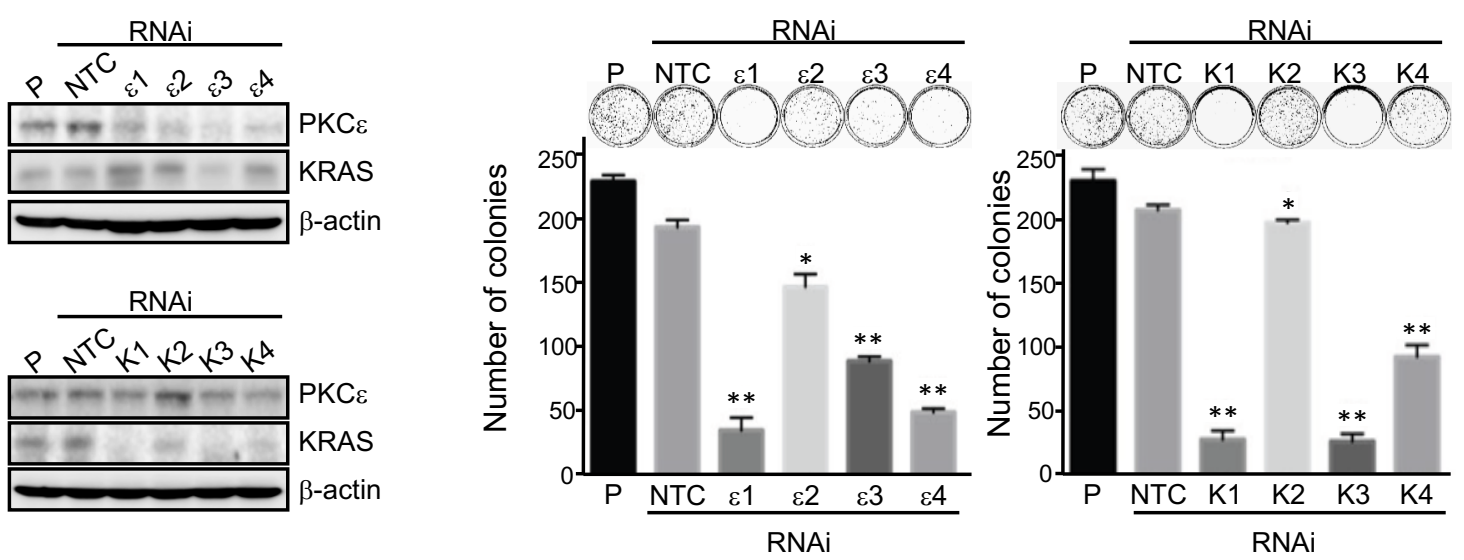

B
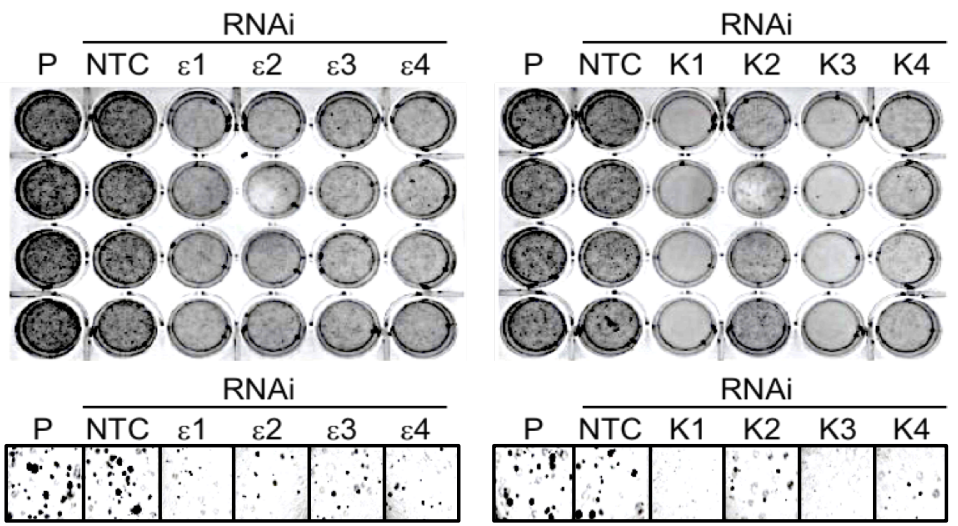

C
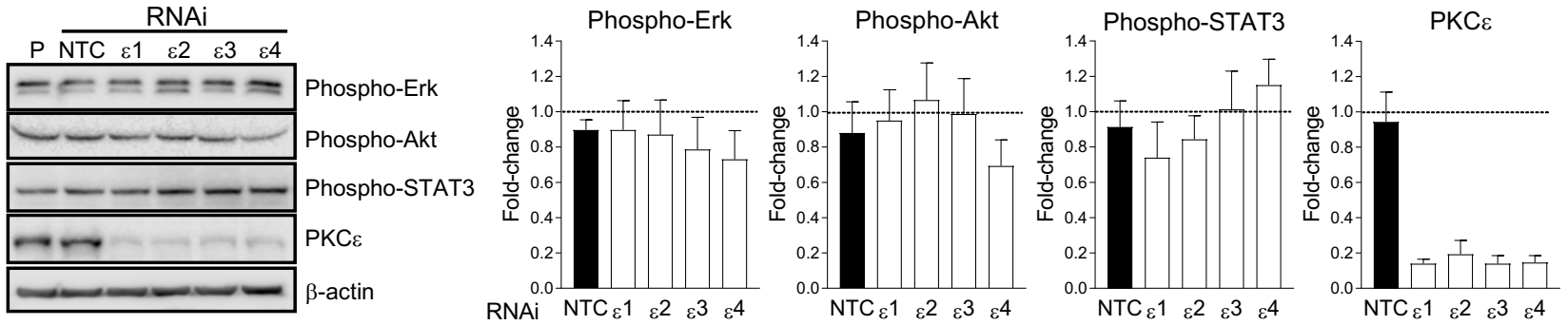

D
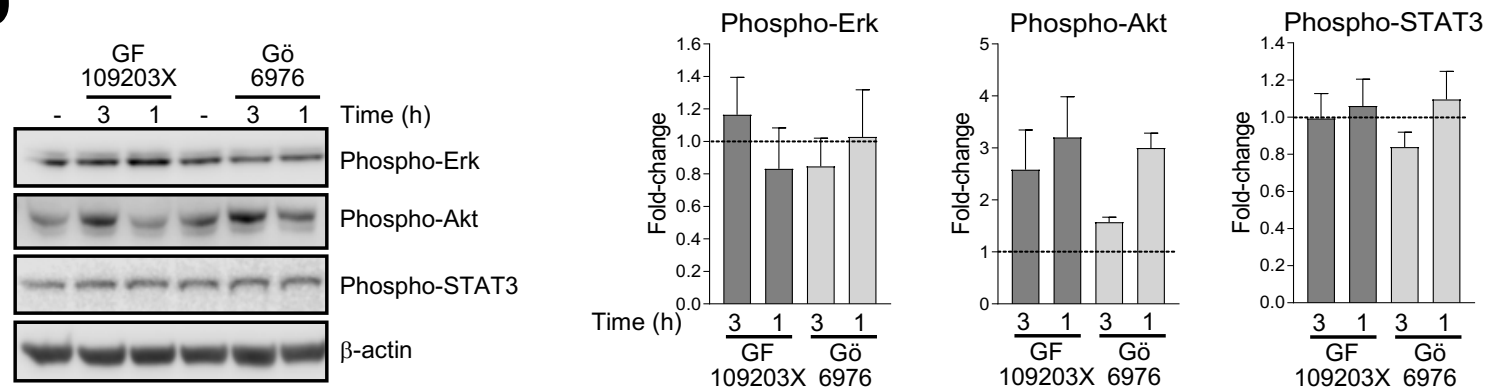
Figure 4

A
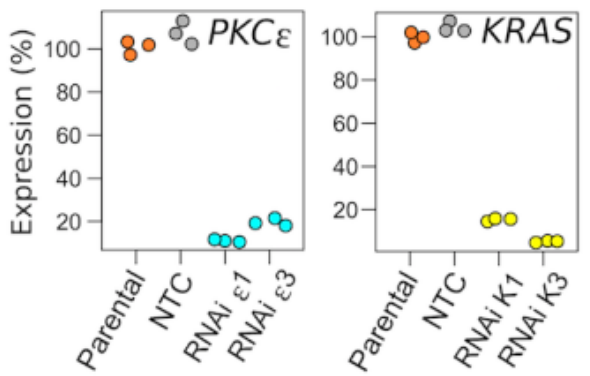

C

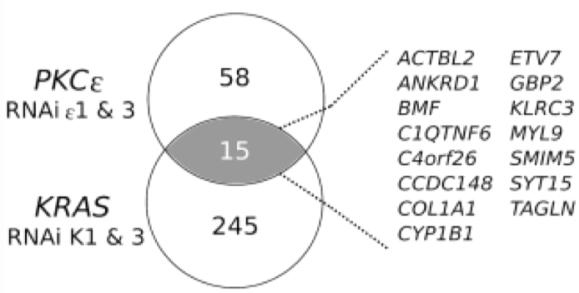

D

\begin{tabular}{|c|c|}
\hline & \\
\hline $\begin{array}{r}\text { Validated AP1 TF targets } \\
\text { ECM organization }\end{array}$ & \\
\hline $\begin{array}{l}\text { ECM organization } \\
\text { ell surface interactions }\end{array}$ & \\
\hline Collagen degradation & \\
\hline Hematopoietic cell lineage & \\
\hline Jak-STAT signaling pathway & \\
\hline signaling network & \\
\hline adation of the ECM & \\
\hline & \\
\hline Activation of RAS signaling & \\
\hline Integrin cell surface interactions & \\
\hline VEGFR signaling & \\
\hline PDGFR-beta signaling pathway & \\
\hline ECM-receptor interaction & \\
\hline Hematopoietic cell lineage & 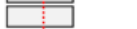 \\
\hline$\square$ KRAS & \begin{tabular}{l|lll} 
& 1 & 1 & \\
2 & 3 & 4 & 5
\end{tabular} \\
\hline$\ldots \ldots .05$ & \\
\hline
\end{tabular}

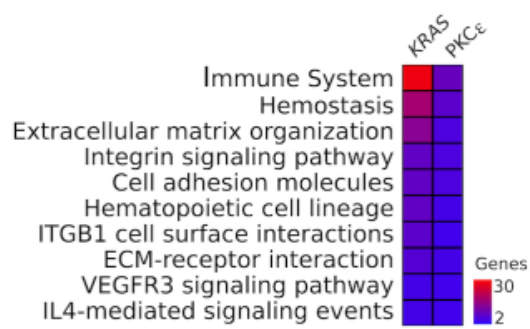

B
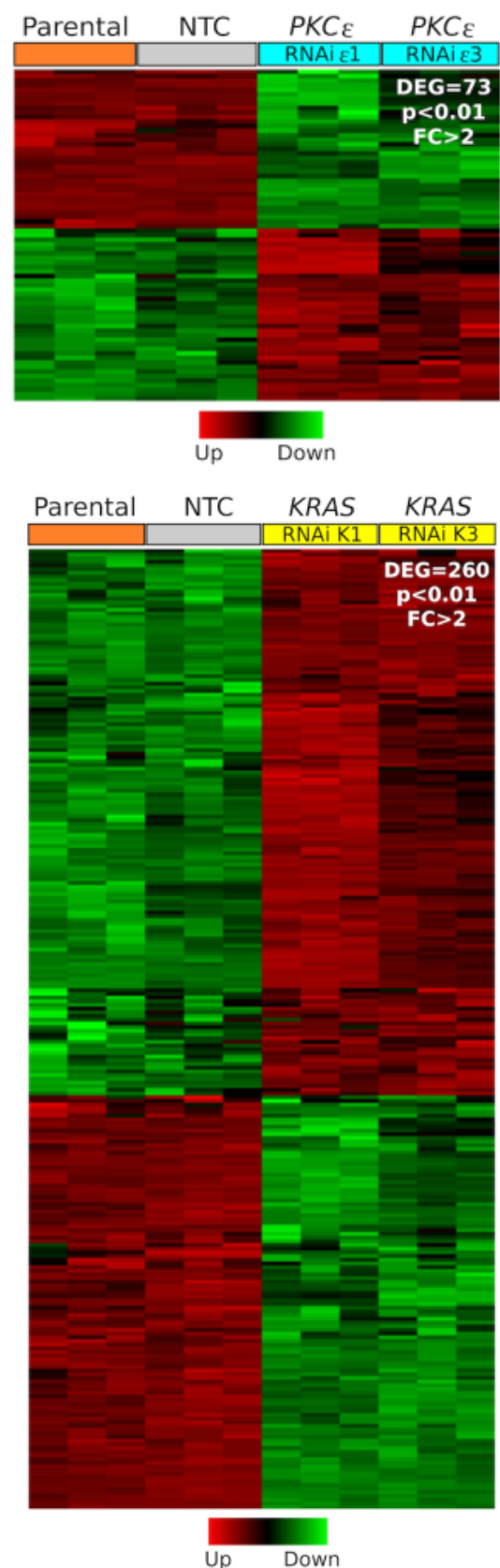